soquired a habit of hard drinking, and had sufiered from attucks of dyspepois and a morbid sensibility of the nervous system. On the present occasion, he bad been drinking to excess for two or three weeks, and eating scarcely any food. I was sent for on account of a copious bleeding from his nose, which he had, however, stopped before my arrival, by the application of turpentine on cotton wool. There were large ecchymoses on his arms, hands, thighs, and legs, and some smaller ones on his head. They had appeared at various times within the three previous days, and some of the earlier ones were already fading. In the centre of each patch of ecchymosis there was a small hard tumour, over which the skin was quite white. These tumours or nodules felt almost as hard as cartilage, and were proportionate in size to the ecchymoses : where these were as large as the hand, the tumours were as big as a horsebean; where the purple patches were smaller, so were the tumours. The pulse was bounding but compressible; there was great debility, and the limbs were rather tremulous. He was treated with lemon-juice and decoction of cinchona with dilute sulphuric acid, and was directed to take such nourishing food as his appetite would permit. He improved during the next two days. On the 15 th, the patches of ecchymosis had faded considerably, and the nodules were diminished in size.

I was sent for again on the 18th, and found the patient labouring under a rather severe attack of erysipelas of the face and head. He took quinine and a nourishing diet nitrate of silver was applied externally; and on the 26th, he was convalescent.

Remarks. I consider that the small hard tumour situated in the centre of each patch of ecchymosis consisted undoubtedly of the fibrin of the blood, which had coagulated quickly at the point where it escaped from the ruptured ressel, whilst the serum and globules spread all round in the cellular tissue. The above case of purpura did not differ in any essential particular from that important variety of the disease we call scurvy; and although in some cases of scurvy the blood seems to have lost its power of coagulating, there are other cases in which this fluid coagulates more quickly and strongly than usual. This was remarked by Dr. Milman, who wrote on scurvy in 1782, and attributed the disease to impaired nutrition of the blood-ressels. Jir. Budd has since observed that the blood in many cases of seurvy retains its power of coagulating undiminished.

Although I have not observed the above mentioned little tumours in any other case of purpura, I cannot consider this to be a solitary instance of their presence. I think it probable that they may have been passed over, as belonging to what is called purpura urticaria. The tumours however, have no relation to the wheals of urticaria, and do not in the least resemble them.

Brokville Street, April 1856.

\section{THE OPERATION FOR THE EXTRACTION OF CATARACT.}

By Augustiv Prichard, Esq., Bristol.

Ir is as disagreeable to report cases of unsuccessful operation as it is satisfactory to narrate those with an opposite result; but, at the same time, the greater amount of information generally conveyed by the former renders the task a matter of duty; and I therefore send the following unusual and unsuccessful cases for publication in the JOURYAL.

CASE I. In a patient operated upon by the late Mr. Estlin, there had been an escape of vitreous humour during the operation, but the sight immediately afterwards was good: hæmorrhage came on subsequently, filled the space between the lids, and, separating the corneal flap, completely destroyed the sight. The patient had vomited in the right, and had probably ruptured some Jitile ressel of the choroid coat, which poured out the blood. The other eye was operated on at the same time, and ultimately did well, although the convalescence was tedious and troublesome.

CASE II. I operated, in the autumn of 1855 , on the left eje of an old man whose right eye had become staphylomatous after an unsuccessful cataract operation. The left eye had been injured by a blow many years ago, and cataract, with adhesion of the iris to the capsule, had resulted; subsequently the right eye became blind, and he came up for sequently the right eye becamed in May 1855. No union of the flap (made by an upper section of the cornea) took place, and the eye became staphylomatous. As a last chance, I operated upon the left eye six months afterwards, and extracted the lens without any great difficulty. The only unusual occurrence which I noticed was a drop of: blood on the knife whilst it was in the anterior chamber, from which I concluded that the cornea was in an unhealthy state. The pupil was adherent to the capsule, and irregular in its outline. Hæmorrhage came on in the night; the eye filled; and a large black clot protruded between the ejelids, having the appearance of melanotic growth from the eyeball; and, after a good deal of suffering, the eye sloughed, and the patient became totally blind.

I have in one instance noticed a similar occurrence after an operation for the removal of the anterior part of a staphylomatous eye, but I have never heard of other cases of hæmorrhage following the extraction of cataract. In each of these instances there must have been some peculiarity in the nutrition of the eyc, as there had been nothing untoward in the operations.

The following cases are of a different nature.

Casz III. A. G., aged 71, a healthy old man, with excellent eyes for operation, came under my care with fully formed amber-coloured cataract in the left eye, and with the lens so opaque in the right that he could barely see to go about.

I operated on the left eye on the 3rd of December, 1852, and made a lower section in a most satisfactory manner. After rupturing the capsule as usual, upon raising the lid to make the requisite pressure to ensure the escape of the lens, a little clear and bright vitreous humour flowed out and I just caught sight of the lens falling backrards and outwards to the lower part of the eye. It went completels out of sight, leaving the pupil perfectly clear and circular. I made no attempt to get at the lens, but fastened up the eye in the usual way, and put the patient to bed. He had no bad symptoms, and in ten days he went home with good sight.

He returned in little more than a month, complaining that his sight was becoming dim again; and, upon examination, the pupil was found to be drawn downwards and outwards, and the cataract was in sight below. At the same time, the patient could see tolerably well with this ere. A little inflammation ensued, but it was soon relieved.

I subsequently performed two operations on the same eye, to remove the lens and enlarge the pupil, but withont success. At the ome time as the right eye became more dim, the little sight which still remained in the left became more valuable.

On the 5th of October, 1855, I operated on his other eye (his age being now 74), and made the upper section through a well marked arcus senilis, and removed the lens, He had no bad symptoms, and was well in ten days after the operation, and now enjoys good sight with the right eye.

CABE IV. On the 19th of Feb. of this year I operated or the left eye of a woman, aged 63, who had been blind for nearly two years. After completing a fair lower section, I introduced a curette to divide the capsule, when some clear vitreous humour began to protrude; and although the lons seemed at first to be adherent to the margin of the pupial it gradually fell backwards, and disappeared from view. She could see immediately afterwards sufficiently well to distinguish my hands, face, etc., but she complained of great aching of the eje. Considerable inflammation followed, but there was nothing approaching to suppuration, 
and ahe ultimately recovered, and went home with fair sight.

Bince her return home I have heard that she has had an attack of inflammation again, but that it subsided, and I haro no further report as to her sight. It is to be feared that the presence of a lens in an unnatural part of an eje thus disposed to inflammation must ultimately lead to very sorious ovil, and I do not feel at all sanguine respecting the isue of the case.

RExarrs. Within the last few weeks the question as to the propriety of operating upon both ejes at one sitting has been again mooted in our JovkNAL, and the house-surgeon of tho Leicester Infirmary has remarked that Mr. Paget is the only surgeon in the United Kingdom who adopts this mode of practice. The inaccuracy of this statement has doubtless arisen from the fact that unless there is something peculiar in the cases, they are not published, and one surgeon does not know what his neighbour does. The late Mr. Estlin frequently operated on both eyes, and I hare, in many instances, done the same, and I think that the advantages, or otherwise, to the patient may be thus easily stated.

A patient has a better chance of recovering fair sight (with one eje, or both) when both are operated upon at the same time than when only one is operated on, and the patient does not undergo the second operation; but a patient who undergoes an operation, and, after a suitable period, submits to the second, has a better chance of good sight (with one eye, or both) than he who has both eyes operated on at the samę sitting. Hence the point becomes reduced to a matter of convenience; as, for example, in the case of a poor person of advanced age who applied for aid from some distant place, and who was not likely to be able to come again for the second operation provided the first should turn out in an unsatisfactory manner, it would be more to his interest to operate on both eyes at once. This has been my usual guidance in these cases, and the result has been as nearly as possible in accordance with what I have stated.

\section{Association Atlediral êdownal.}

SATURDAY, MAY 3RD, 1856.

\section{THE PRINCIPLE OF DIRECT REPRESENTATION IN MEDICAL REFORM.}

Ir there is one thing more than another which we may boast of as Englishmen, it is, that we are allowed, or rather, that we have maintained, the right of governing our own movements. The very conciousness that, by a greater effort, or by more sustained perseverance, we might throw off some incubus of an abuse, enables us to bear it, grumblingly, it may be, yet without a sacrifice of our moral independence. If we allow this fundamental principle to fall into abeyance, we sacrifice the dearest privilege of existence-the one thing that makes man proud to be. That there are circumstances in which dictation is necessary, where the more enlightened must pass unwelcome laws for the less enlightened, is undoubted; but surely such an argument cannot apply in the present instance, where the class to be legislated for is, in education, at least equal-we think, superior-to their legislators, in moral and scientific status. We cannot, nor do we wish, to offer our readers an essay on the Rights of Man ; but we must recall these first principles to their memory, in order forcibly to impress upon them the fault of the system of medical government which, we hear it whispered, is to be foisted upon us.

We advocated Mr. Headlam's Bill, because it promiced to give us a common interest, and a tolerably uniform control orer the highest interests of our beloved profesoion. Who can deny that it had faults? Who can assert that it gave all we wish for, or avoided all that was objectionable? But at least it left untouched the only principle which, among all the errors and abuses of our political system, offers the consolation of a better adrent-the principle that each individual might directly or indirectly influence, or bring to bear, his views regarding the government of his class.

There was room for due fermentation, which would necessarily have ensued; and sooner or later, with all the goodwill which really animates the majority of our professional brethren, wo should have seen, in the place of a muddy, pulpy must, a clear, fragrant, full-bodied wine.

And now? $\Lambda$ system of government nominees is said to be looming in the future, who, probably under the control of a person or persons utterly irresponsible to the twenty thousand medical gentlemen of the country, will supervise and regulate their interests. Without connexion with or influence orer the members of the Government, appointed under the pleasure of, or for a brief period by, a Minister of the Crown; without boroughs or appointments to give away,-what power will they possess of resisting sinister influences from all sides? what moral force will they have to fall back upon, and to recover strength from, in the inevitable battles for the rights of their brethren? What guarantee shall we have that men, who love their profession more than themselves; that men of high honour and integrity, or even men of high literary attainments and professional position, will be appointed, - what guarantee shall we possess that the Government nominees will truly and adequately represent and guard the interests of the profession?

We know that all government is but a system of compromises, and we admit that large numbers of the profession would rather have a measure of medical reform somewhat modified by the Government, than none at all; but we think the promoters of Mr. Headlam's Bill will ponder long and deeply ere they consent to conditions which wipe out so essential a clause as that which provides for a direct representation in the Medical Council of the great body of the profession. We believe, however, that no determination will be come to without due consideration; and therefore we rely with confidence upon the judgment of the Reform Committee of the Association.

\section{T H E W E K}

THrs week the Summer Medical Session for 1856 commences. Had the war continued, we should have expected to have heard of an unusual number of entries at the hospitals ; this cannot now be expected, as to all appearances we have entered into the piping times of peace, which promise to last for the remainder of the century. If we may not expect more students this year, it is pretty certain that the metropolis will welcome home again many wellknown members of the profession, who have earned fame for themselves on the bloody fields of the Crimes. There can be no doubt that British surgeons treated their patients much more successfully (with the exception of the severer operations where the patients were too much roduced to reply to their skill) in the Crimean campaigns 